\title{
Charge Storage in Flower-like ZnS electrochemically deposited on $\mathrm{TiO}_{2}$ Nanotube
}

\author{
Biplab Sarma ${ }^{\mathrm{a}}$, Rupashree S. Ray ${ }^{\mathrm{a}}$, and Mano Misra ${ }^{\mathrm{a}}$, b, 1 \\ ${ }^{a}$ Metallurgical Engineering Department, University of Utah, Salt Lake City, UT 84112, USA \\ ${ }^{\mathrm{b}}$ Chemical Engineering Department, University of Utah, Salt Lake City, UT 84112, USA
}

Keywords: Titania Nanotube, electrochemical Capacitor, Zinc sulfide, Pseudocapacitance, Supercapacitor, Electrodeposition

\begin{abstract}
A composite electrode comprising of flower-like zinc sulfide/titania nanotube have been synthesized through electrodeposition technique for supercapacitor application. The morphology and phase evolution of the electrode were analyzed using scanning electron microscopy (SEM) and X-ray diffraction (XRD) techniques. The cyclic voltammetry studies of the electrode indicated that a high specific capacitance $\left(226 \mathrm{~F} \mathrm{~g}^{-1}\right)$ can be achieved in the electrode together with high stability during large charging conditions.
\end{abstract}

\section{Introduction}

The charge storing mechanism of electrochemical capacitor can be electric double-layer (EDL), the fast faradic redox type (pseudocapacitor) or a mixture of both [1-5]. In the EDL capacitor, electric energy is stored through the non-faradic charge separation at the electrode/electrolyte interface $[1,2]$. In case of pseudocapacitors, redox reactions that occur between the electrode and the electrolyte are largely responsible for the charge storage [2,5].

${ }^{1}$ Corresponding author: mano.misra@utah.edu 
As a wide band gap semiconductor material, ZnS finds enormous applications in optical, photocatalytic, sensor and in the electronic fields [6]. However, in spite of its peculiar electronic properties, this class of material has not been studied well for its electrochemical charge storing/supercapacitance behavior. The feasibility of using $\mathrm{ZnS}$ as supercapacitor electrode was introduced in a study by Jayalakshmi et al [6], however there has not been much efforts in this area following this study.

Here, we have evaluated the supercapacitance behavior of titania nanotube (T-NT)/ZnS composite electrode prepared using a straightforward electrodeposition method. The presence of porous substrate like T-NT has been reported to show remarkable enhancement in the supercapacitance behavior in composite electrode materials [5, 7]. Further, T-NT substrate is easy to synthesize, exhibits higher surface area coupled with excellent chemical stability, and non-toxic in nature [8].

\section{Experimental studies}

\subsection{T-NT Substrate Fabrication}

Titantium samples $(0.1 \mathrm{~mm}$ thickness and $10 \mathrm{~mm}$ x $15 \mathrm{~mm}$ ) were roughly polished (with 600 grit $\mathrm{SiC}$ emery paper) and ultrasonically cleaned in a solution of acetone and isopropyl alcohol (1:1). Subsequently, the coupons were anodized potentiostatically in an electrolyte $(0.5 \mathrm{wt} \%$ ammonium fluoride and $10 \% \mathrm{H}_{2} \mathrm{O}$ ) at $40 \mathrm{~V}$ for 1 hour. Subsequently, the anodized titanium samples were annealed in air at $500^{\circ} \mathrm{C}$ for 2 hours.

\subsection{Electrochemical Deposition of $\mathrm{ZnS}$}

Electrodeposition of $\mathrm{ZnS}$ on T-NT surface was carried out in an aqueous solution of $10 \mathrm{mM}$ zinc chloride and 0.5 M thiourea. A 3-electrode based electrochemical workstation (Gamry Reference 
600) with annealed T-NT coupon as working electrode, platinum coil as counter electrode and a saturated $\mathrm{Ag} / \mathrm{AgCl}$ electrode as reference constituted the electrochemical deposition setup. Galvanostatic depositions were carried out at three different current densities of $-0.1,-0.5$ and $1.0 \mathrm{~mA} \mathrm{~cm} \mathrm{~cm}^{-2}$ for $30 \mathrm{~min}$. The deposition bath was constantly stirred at $170 \mathrm{rpm}$ during experiments.

\subsection{Characterization}

Examination of the surface and cross sectional morphology of T-NT and T-NT/ZnS samples was performed using a field emission scanning electron microscope (FE-SEM, Hitachi S-4800). The XRD analysis of the samples was carried out using SIEMENS D5000 diffractometer with copper $\mathrm{K}-\alpha$ radiation.

\subsection{Electrochemical Measurements}

The electrochemical properties of the T-NT/ZnS electrodes were evaluated by conducting cyclic voltammetry (CV) and electrochemical impedance spectroscopy (EIS) experiments in $0.1 \mathrm{M} \mathrm{LiCl}$ using a potentiostat (GamryReference 600), connected to a 3-electrode setup consisting of the T$\mathrm{NT} / \mathrm{ZnS}$ sample as the working electrode, platinum coil as the counter electrode, and saturated $\mathrm{Ag} / \mathrm{AgCl}$ electrode as a reference electrode. Potentiostatic EIS tests were carried out at $0 \mathrm{~V}$ (vs reference) with perturbation amplitude of $10 \mathrm{mV}$ in the frequency range of $100 \mathrm{~Hz}$ to $25 \mathrm{mHz}$.

\section{Results and Discussion}

Anodization of Ti produced self-organized and vertically aligned nanotube array (T-NT) as shown in Fig. 1a. The nanotubes were found to have an average diameter of $\sim 90 \mathrm{~nm}$, length of $\sim$ $1.5 \mu \mathrm{m}$ (inset Fig. 1a) and wall thicknesses in the range of 15-20 nm. 
The morphology of the $\mathrm{ZnS}$ deposit on T-NT substrate at various deposition current densities $(i)$ are shown in Fig. 1(b-d). Deposition at $i=-0.1 \mathrm{~mA} \mathrm{~cm}^{-2}$ resulted in a foamy ZnS layer on the TNT substrate as shown in Fig. 1(b \& inset). At this current density, most of the substrate was uniformly covered by the deposit, and at some locations, the transformations of the foamy deposit to a nano-petal-like ZnS phase was also observed (Fig. 1b). When $i$ was increased to -0.5 $\mathrm{mA} \mathrm{cm} \mathrm{cm}^{-2}$, a drastic morphological change in the $\mathrm{ZnS}$ phase was noticed. The foamy $\mathrm{ZnS}$ was completely transformed to nano-petal-like morphology (Fig. 1c \& inset). Further, a number of nano-petals were connected through their base and such arrangement resulted in a flower-like arrangement of the $\mathrm{ZnS}$. In this case also, a uniform covering of the $\mathrm{ZnS}$-flower-like deposit through the entire T-NT substrate was observed. The size range of the nano-petals in the ZnSflowers was approximately 10-20 nm (inset Fig. 1c). Upon further increase in $i\left(-1 \mathrm{~mA} \mathrm{~cm}^{-2}\right)$, severe agglomeration of the nano-petals was observed (Fig. 1d \& inset). Such agglomeration might have resulted in the formation of irregular shaped mico-sized $\mathrm{ZnS}$ bundles — these bundles looked like numerous $\mathrm{ZnS}$ nano-petals stitched together as shown in the inset of Fig. 1d. It is to be noted that previous studies also witnessed the formation of various morphologies of the deposited phase based on the electrodeposition potential and current densities primarily due to the non-uniform current distribution as well as the tendency of the electrodeposit to form a more thermodynamically stable morphology/shape [3,9]. For example, electrodeposition of platinum resulted in the transitions between various morphologies (hemispherical, nanoflower, nanodendrite) depending on the deposition potentials [9].Therefore, the formation of bundle-like morphology of the $\mathrm{ZnS}$ phase observed in our case may be a thermodynamically favorable response of the deposition behavior. It is to be noted that the electrodeposition process resulted in only on the surface deposition of $\mathrm{ZnS}$ on the T-NT, there was no penetration of the sulfide phase 
into the pores of the nanotubes. Similar deposition behavior has also been reported in some earlier studies $[7,10]$.

The XRD profile for the T-NT/ZnS electrode synthesized at $i=-0.5 \mathrm{~mA} \mathrm{~cm}{ }^{-2}$ is shown in Figure 2. The XRD peaks suggested the formation of predominantly cubic crystalline phase along with the hexagonal phase of the ZnS (JCPDS no. 05-0566) [6]. Please note that some of the peaks from the anatase phase of the T-NT as well as Ti-substrate can also be observed in the XRD profile.

The supercapacitance behavior of the electrodes obtained after various deposition conditions has been analyzed using $\mathrm{CV}$ in $0.1 \mathrm{M} \mathrm{LiCl}$ electrolyte in the potential window of -0.4 to $1.1 \mathrm{~V}$. The $\mathrm{CV}$ profiles, recoded at $50 \mathrm{mV} \mathrm{s}^{-1}$ are presented in Fig. 3a. For all electrodes, the $\mathrm{CV}$ curves appeared to be away from the perfect rectangular shape suggesting that the capacitance behavior may be partly due to the pseudo-nature of the electrodes. Moreover, the current responses in the $\mathrm{CV}$ profiles exhibit mirror-image behavior about the zero-current line with rapid current reversals at each potential limit [1,2]. Further, the capacitance of the electrode prepared at $i=-$ $0.5 \mathrm{~mA} \mathrm{~cm}{ }^{-2}$ appeared to be higher than those prepared at $i=-0.1$ and $-1 \mathrm{~mA} \mathrm{~cm}^{-2}$. The reason for the increased capacitance is because of the $\mathrm{ZnS}$ morphology observed in the electrode prepared at $i=-0.5 \mathrm{~mA} \mathrm{~cm}$ (Fig. 1c). The $\mathrm{ZnS}$ nano-petals were uniformly distributed (no agglomeration) along the entire T-NT substrate facilitating optimum access for the electrolyte to intercalate with the sulfide phase during the $\mathrm{CV}$ process. While the deposition at $i=-0.1 \mathrm{~mA} \mathrm{~cm}^{-}$ ${ }^{2}$ produced foamy deposit with lesser weight fraction of $\mathrm{ZnS}$, deposition at higher current density $\left(i=-1 \mathrm{~mA} \mathrm{~cm}{ }^{-2}\right)$ caused extensive agglomeration of the sulfides causing incomplete intercalation with the electrolyte. From the CV curves, the specific capacitance $(C)$ of the T-NT/ZnS electrodes was calculated using the following equation [11,12], 
$C=Q / \Delta V m$

Where $Q=$ half of the total charge from the integrated $\mathrm{CV}$ area, $\Delta V=$ voltage window, $m=$ mass of $\mathrm{ZnS}$ deposit.

Using Eqn. 1, the specific capacitance were calculated to be about 185,137 , and $84 \mathrm{~F} \mathrm{~g}^{-1}$ for the electrodes prepared at $i=-0.5,-1.0$, and $-0.1 \mathrm{~mA} \mathrm{~cm}^{-2}$, respectively.

$\mathrm{CV}$ analysis was also carried out at different scan rates $\left(20-200 \mathrm{mV} \mathrm{s}^{-1}\right)$ using the electrode prepared at $i=-0.5 \mathrm{~mA} \mathrm{~cm}{ }^{-2}$. The profiles, presented in Fig. 3b, demonstrates that the overall shape of the CV curves did not change at higher scan rates suggesting good stability of the electrode at high charging conditions. The specific capacitance (calculated using Eqn. 1) of the electrode at various scan rates is showed in Fig. 3c. The specific capacitance decreased with increase in the scan rate $[11,12]$. The decrease in capacitance is due to the inadequacy in the accessibility of the inner active sites in the T-NT/ZnS electrode by the electrolytic ions at higher scan rate because of diffusion limitations [3,12]. Therefore, a complete intercalation of the sulfide phase by the electrolyte was not achieved at higher scan rates, leading to a decrease in the specific capacitance. There was nearly $60 \%$ decrease in the specific capacitance with increase in the scan rate from 20 to $200 \mathrm{mV} \mathrm{s}^{-1}$ (Fig. 3c). To demonstrate the stability of the electrodes, repeated CV cycling experiments were conducted on the T-NT/ZnS electrode prepared at $i=-0.5$ $\mathrm{mA} \mathrm{cm}{ }^{-2}$. The results are incorporated in the Supplementary Information document.

Fig. 3d shows the Nyquist plot for the T-NT/ZnS electrode (prepared at $i=-0.5 \mathrm{~mA} \mathrm{~cm}{ }^{-2}$ ) with a depressed semicircular region at high frequency domain and a linear curve at lower frequencies. The semicircular profiles indicate the electric resistance between the electrode/electrolyte systems [3]. Further, considerable deviations of the plot from the imaginary axis at lower 
frequencies represent the ionic diffusion into the pores of the electrode suggesting the capacitive nature of the electrode [3]. Therefore, higher conductivity and reduced charge transfer resistance observed in the EIS studies also support the higher capacitive performance achieved in the TNT/ZnS composite electrode.

\section{Conclusion}

Titania nanotubes (T-NT)/ZnS composite electrodes were prepared using a simple electrodeposition process. SEM and XRD analysis were carried out to study the morphology and phases of $\mathrm{ZnS}$ deposit. The cyclic voltammetry tests carried out in $0.1 \mathrm{M} \mathrm{LiCl}$ electrolyte suggested that a high capacitance value $\left(226 \mathrm{~F} \mathrm{~g}^{-1}\right)$ can be achieved in the electrode by suitably optimizing the electrodeposition parameters. The CV results were also supported well by the EIS study conducted on the electrode.

\section{Acknowledgement}

The authors acknowledge U.S. Department of Energy (DE-FC-36-06GO86066) for the financial support supported to carry out the work presented here.

\section{References}

1. Burke A. Ultracapacitors: why, how, and where is the technology. J Power Sources. 2000; 91:3750

2. Zhang Y, Feng H, Wux, Wang L, Zhang A, Xia T, Dong H, Li X, Zhang L, Progress of electrochemical capacitor electrode materials: A review, Int. J Hydrogen Energy 2009;34 :48894899 
3. Sarma B, Smith Y, Jurovitzki AL, Ray RS, Mohanty SK, Misra M, Supercapacitance behavior of porous oxide layer grown on 302 type stainless steel substrate, J Power Sources. 2013;236:103-11

4. Kwak JH, Lee YW, Bang JH, Supercapacitor electrode with an ultrahigh Co3O4 loading for a high areal capacitance, Mater Lett. 2013; $110: 237-240$

5. Sarma B, Smith Y, Jurovirtski AL, Mohanty SK, Misra M, Redox-Induced Enhancement in Interfacial Capacitance of the Titania Nanotube/Bismuth Oxide Composite Electrode, Appl Mater Inter. 2013; 5:1688-97

6. Jayalakshmi M, Rao MM, Synthesis of zinc sulphide nanoparticles by thiourea hydrolysis and their characterization for electrochemical capacitor applications, J Power Sources. 2006;157:62429

7. Ray RS, Sarma B, Jurovirtski AL, Misra M, Fabrication and Characterization of Titania Nanotube/Cobalt Sulfide Supercapacitor Electrode in Various Electrolytes, Chemical Engineering Journal, in press

8. Smith Y, Ray RS, Carlson K, Sarma B, Misra M, Self-Ordered Titanium Dioxide Nanotube Arrays: Anodic Synthesis and Their Photo/Electro-Catalytic Applications, Materials, 2013;6 : 2892-2957

9. Liu J, Wang X, Lin Z, Cao Y, Zheng Z, Zeng Z, Hu Z, Shape-Controllable Pulse Electrodeposition of Ultrafine Platinum Nanodendrites for Methanol Catalytic Combustion and the Investigation of their Local Electric Field Intensification by Electrostatic Force Microscope and Finite Element Method, Electrochimica Acta 2014; 136: 66-74

10. Y. Xie, L. Zhou, C. Huang, H. Huang, J. Lu, Fabrication of nickel oxide-embedded titania nanotube array for redox capacitance application, Electrochim. Acta , 2008; 53: 3643-3649

11. Zhang L, Wu HB, Lou XW, Unusual CoS2 ellipsoids with anisotropic tube-like cavities and their application in supercapacitors, Chem. Commun. 2012;48: 6912-6914

12. Sarma B, Ray RS, Mohanty SK,, Misra M, Synergistic Enhancement in the Capacitance of Nickel and Cobalt Based Mixed Oxide Supercapacitor Prepared by Electrodeposition, Appl. Surf. Sci. $2014 ; 300: 29-36$ 
Figure 1: (a) The top view of the T-NT arrays formed after anodization (inset shows the crosssectional view), morphologies of the $\mathrm{ZnS}$ deposit after deposition at (b) $-0.1 \mathrm{~mA} \mathrm{~cm}{ }^{-2}$, (c) -0.5 $\mathrm{mA} \mathrm{cm}{ }^{-2}$, and (d) $-1.0 \mathrm{~mA} \mathrm{~cm}^{-2}$, the insets show the magnified images of the deposits.

Figure 2: XRD profile of the T-NT/ZnS electrode prepared at $\mathrm{i}=-0.5 \mathrm{~mA} \mathrm{~cm}$

Figure 3: (a) Comparative CV profiles of the T-NT/ZnS electrodes prepared at $\mathrm{i}=-0.1,-0.5$, and $-1.0 \mathrm{~mA} \mathrm{~cm}{ }^{-2}$ (b) $\mathrm{CV}$ curves for the T-NT/ZnS electrode prepared at $\mathrm{i}=-0.5 \mathrm{~mA} \mathrm{~cm}$ at various scan rates (c) Variations in the specific capacitance for the T-NT/ZnS electrode prepared at $\mathrm{i}=$ $0.5 \mathrm{~mA} \mathrm{~cm}^{-2}$ as the function of scan rate (d) Nyquist plot of the T-NT/ZnS electrode prepared at $\mathrm{i}=-0.5 \mathrm{~mA} \mathrm{~cm}{ }^{-2}$ 


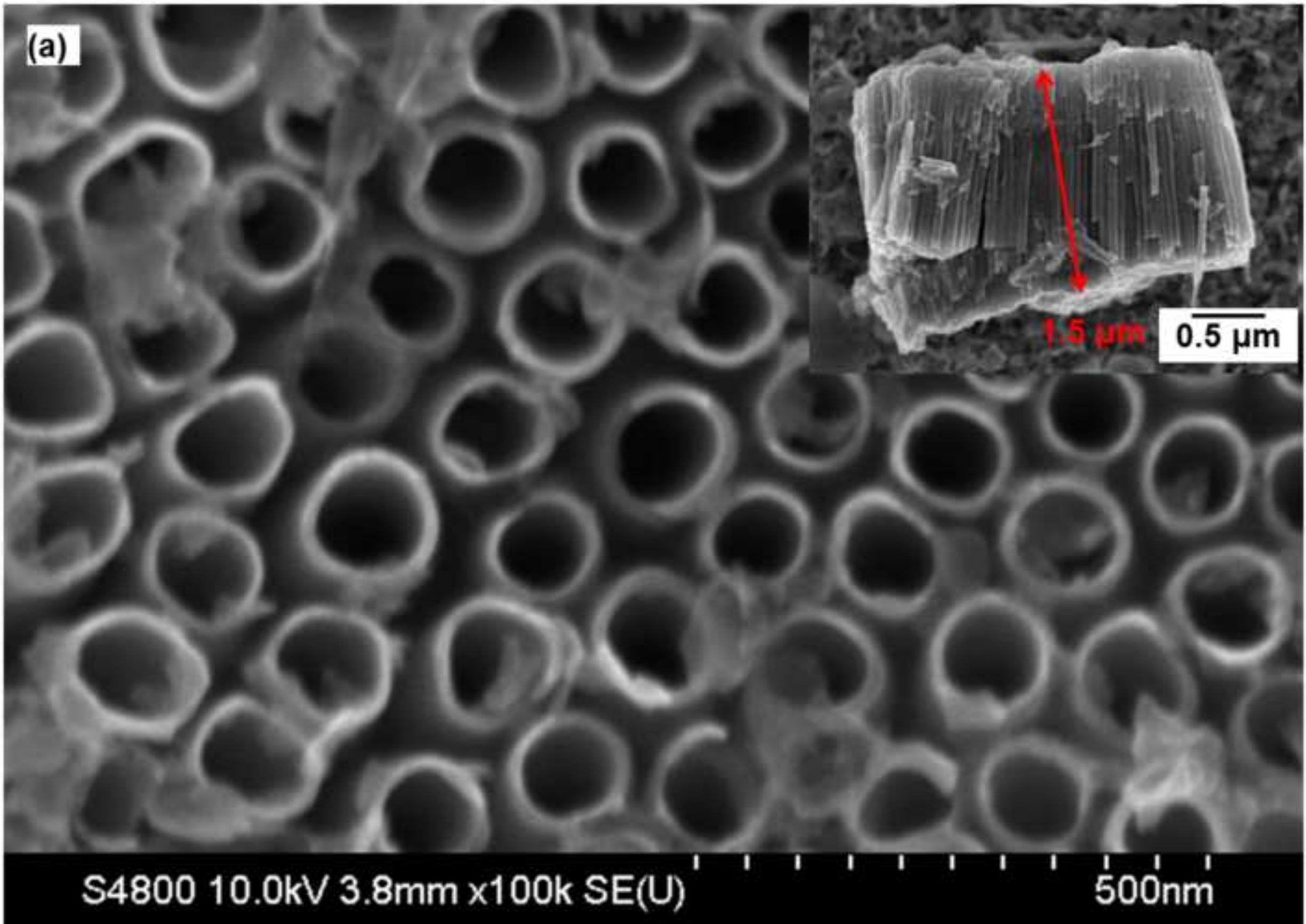

S4800 10.0kV 3.8mm x100k SE(U) $500 \mathrm{~nm}$ 


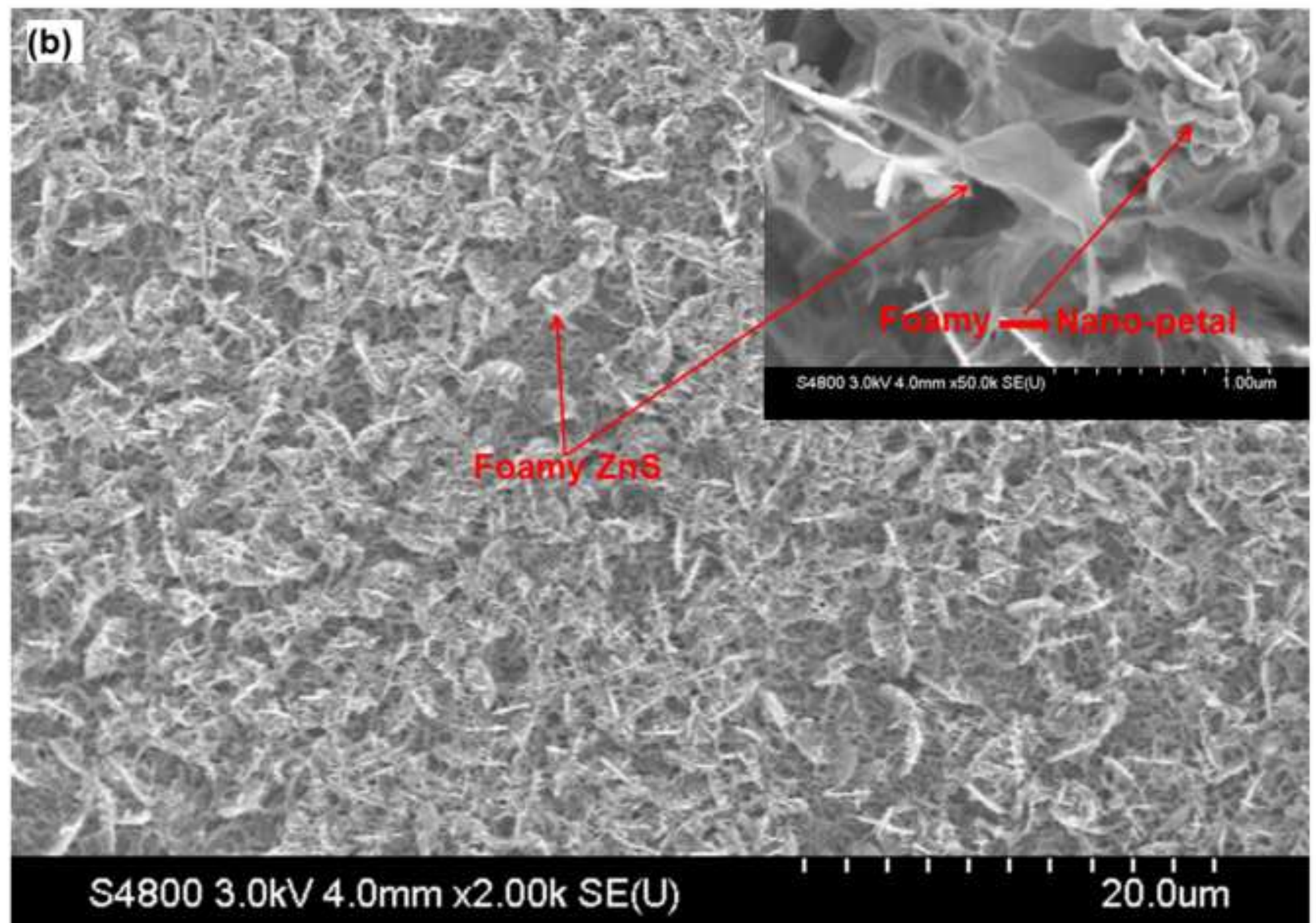



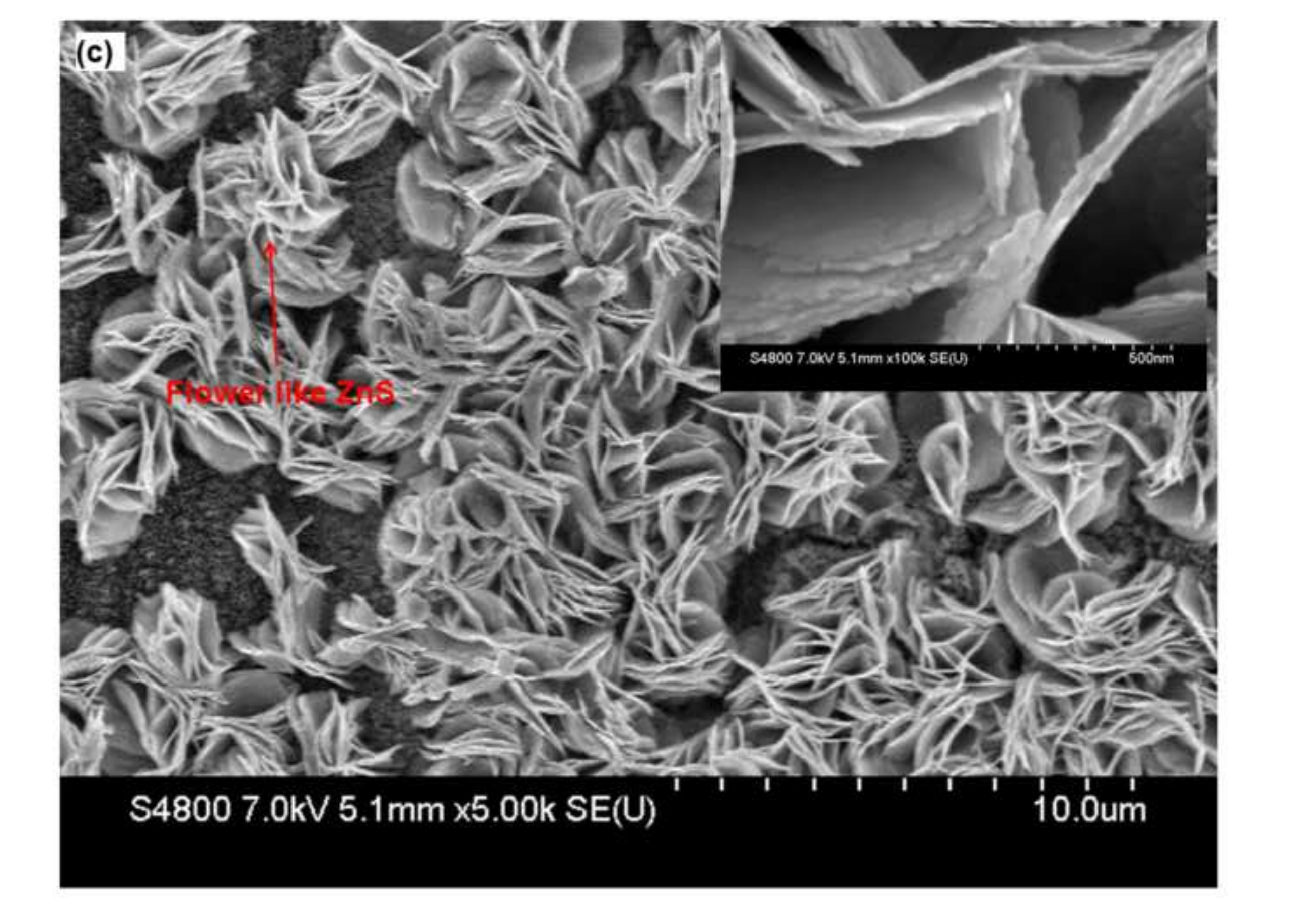


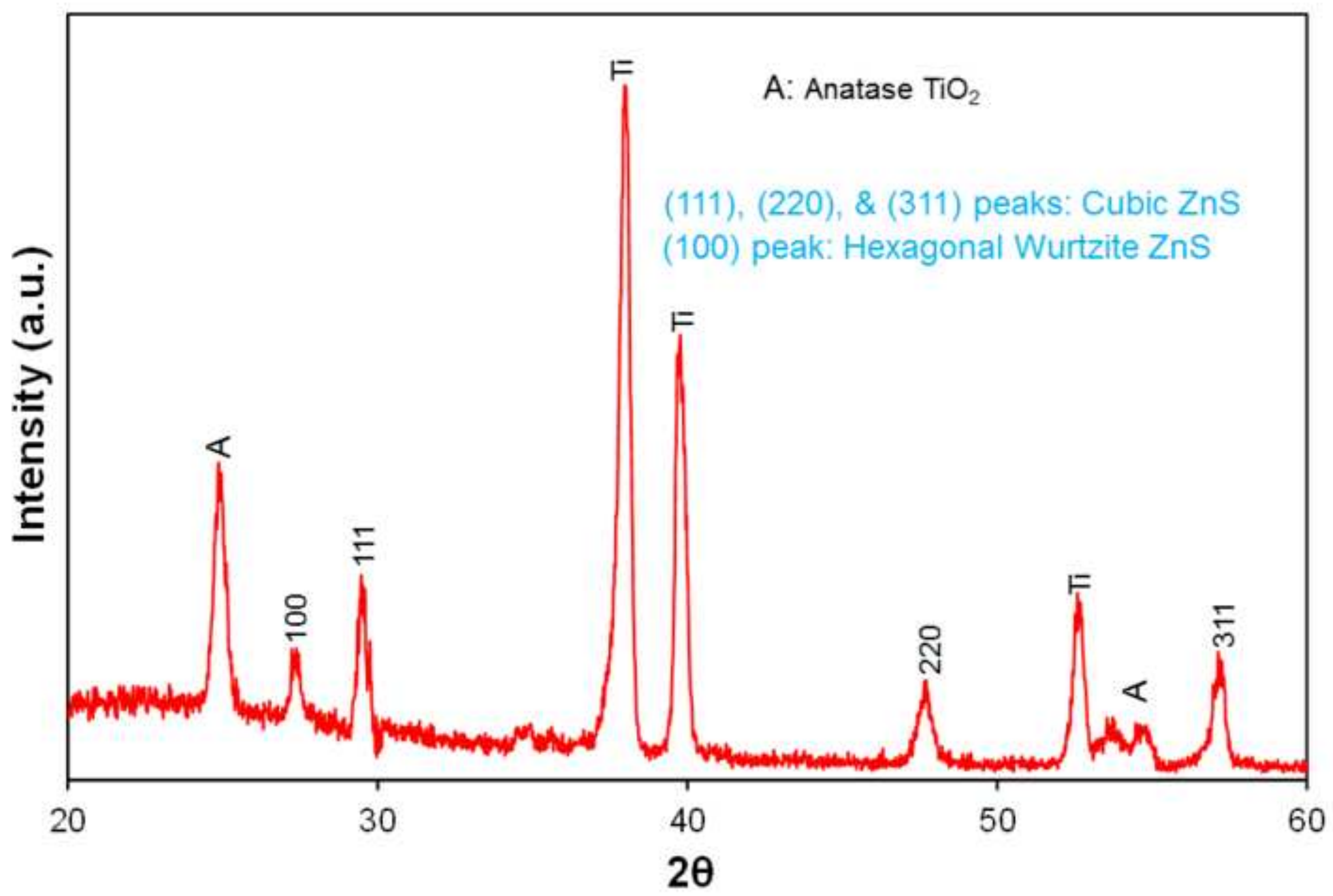




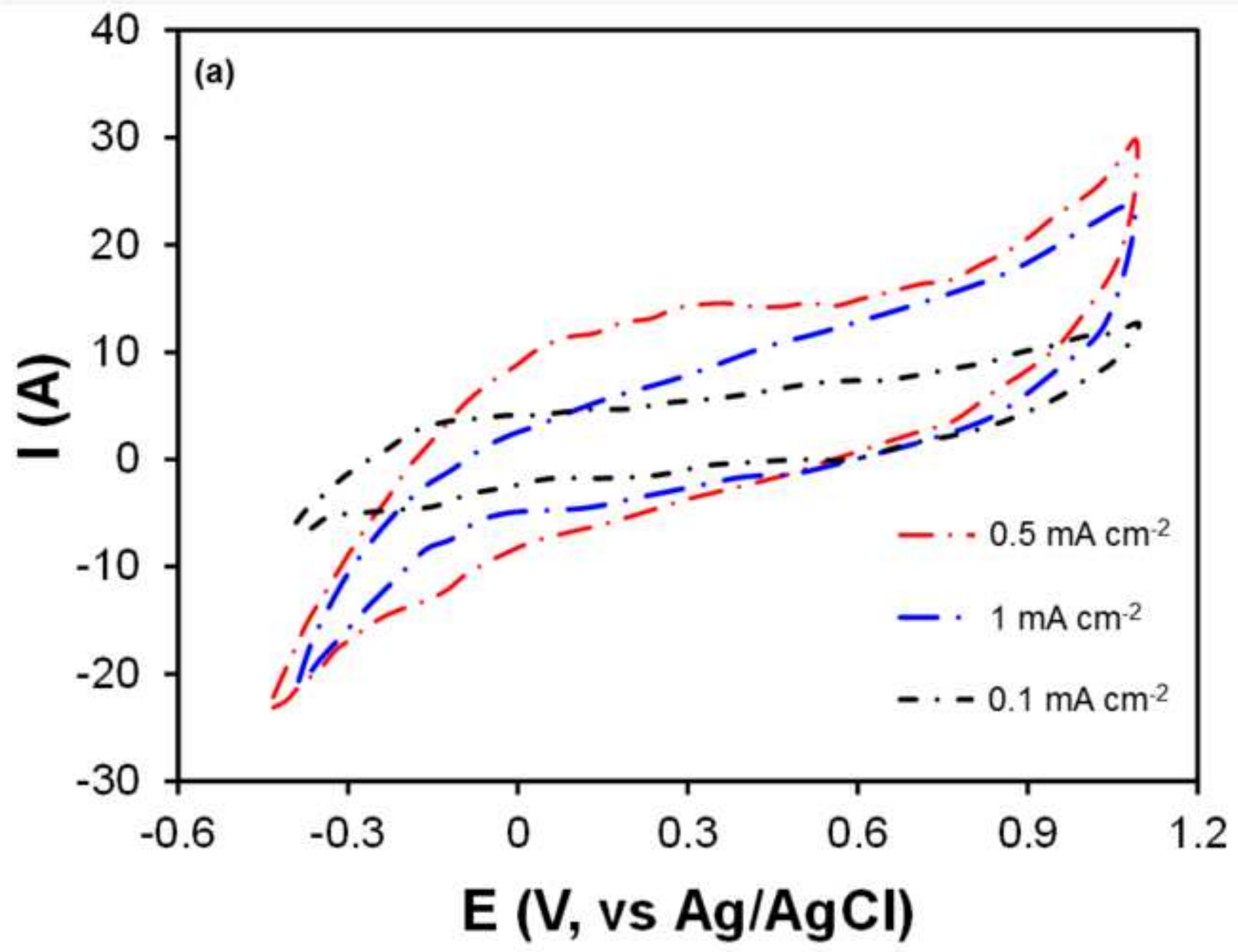




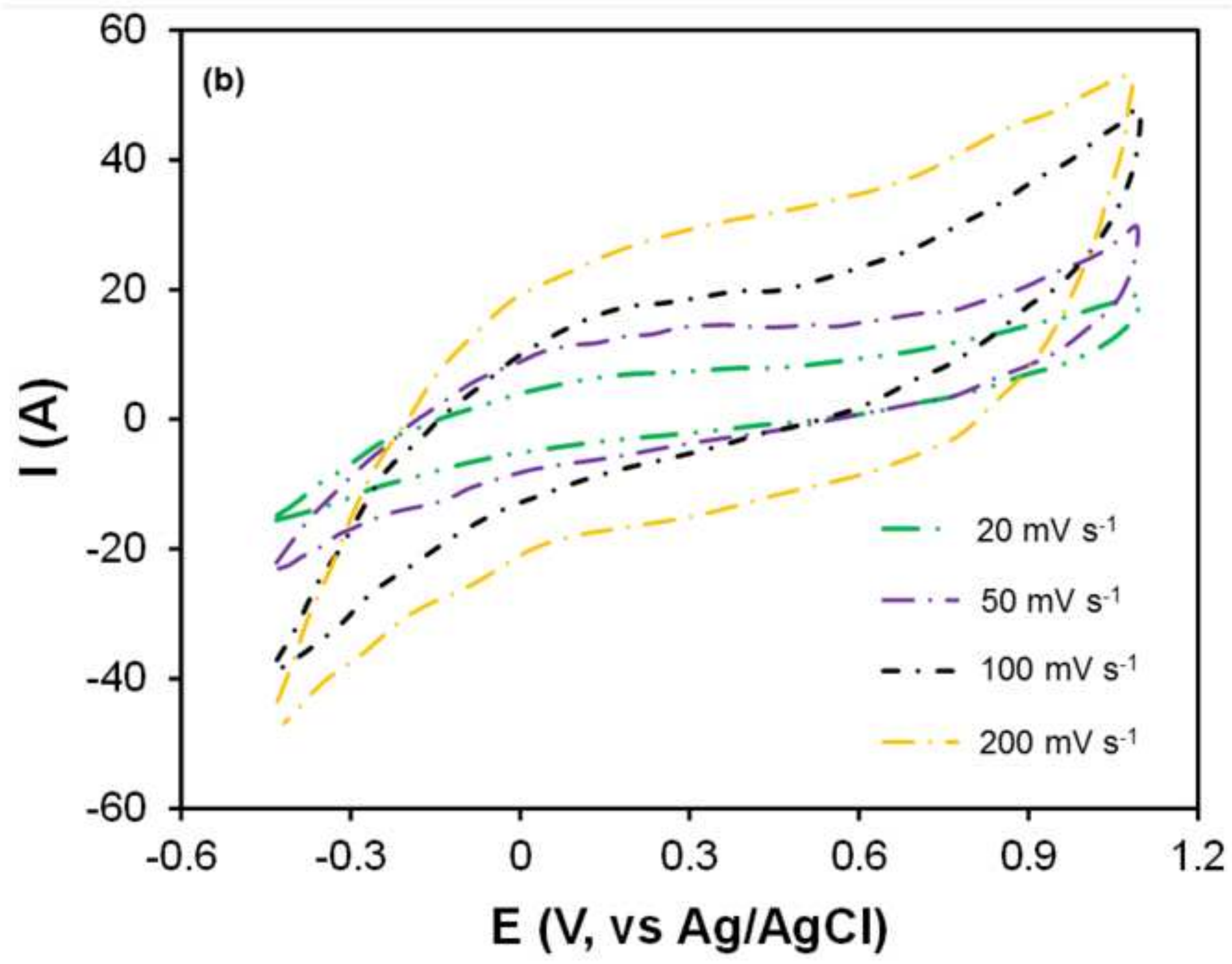




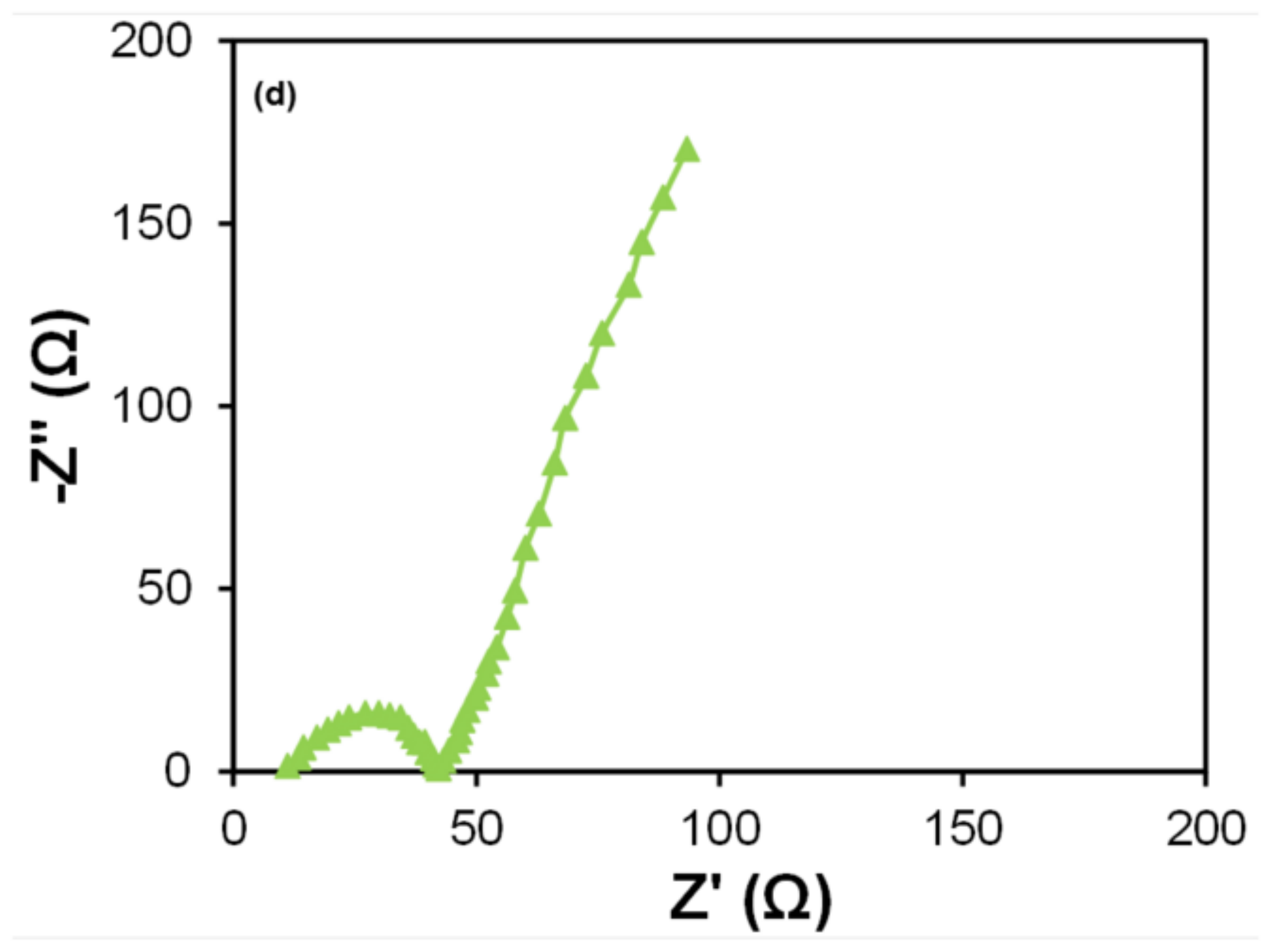




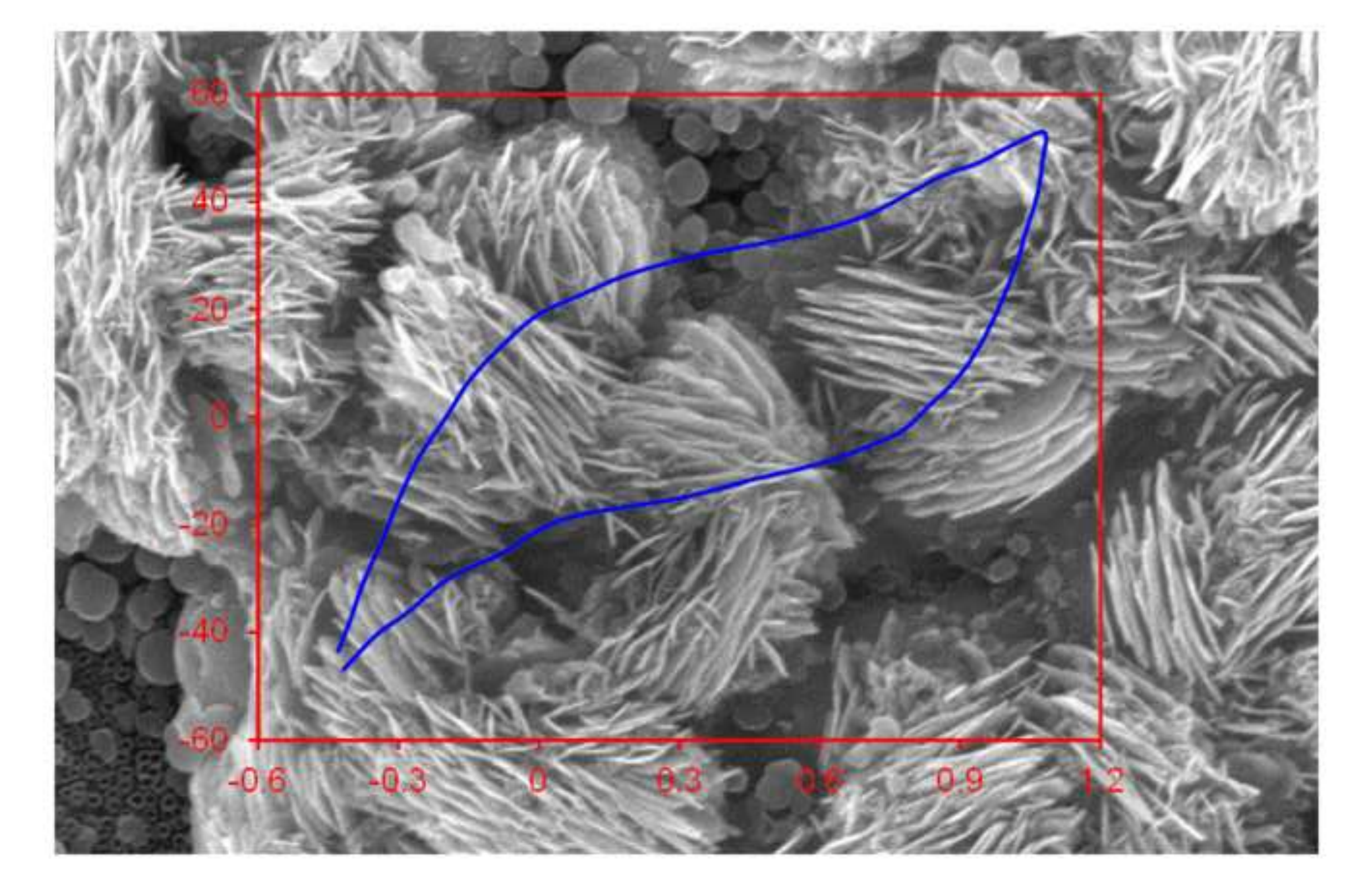$$
\text { . }
$$

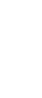

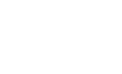
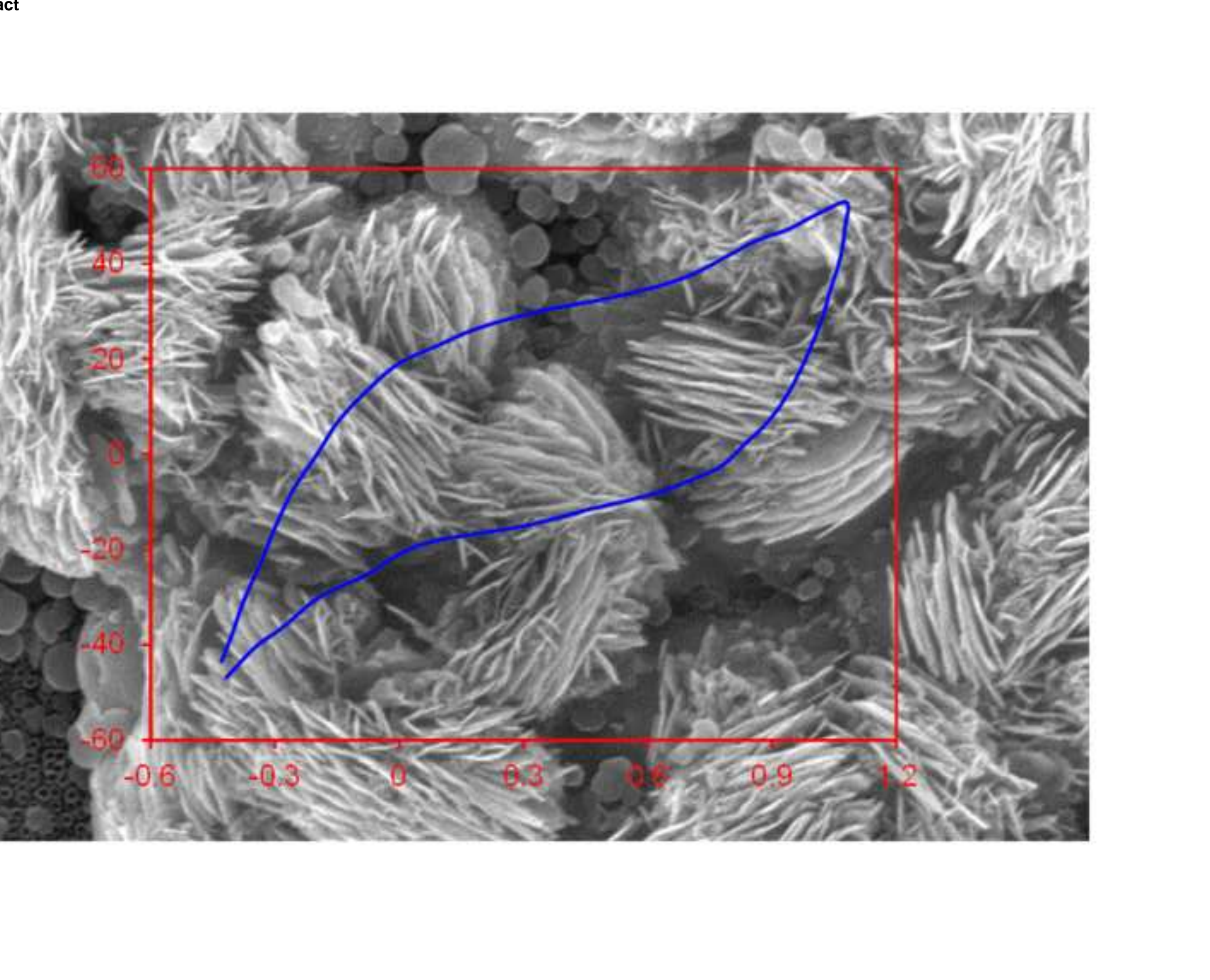